\title{
The landscape of COVID-19 clinical trials in Latin America and the Caribbean: assessment and challenges
}

\author{
Sarah Carracedo ${ }^{1}$, Ana Palmero ${ }^{1}$, Marcie Neil ${ }^{1}$, Anisa Hasan-Granier ${ }^{1}$, Carla Saenz ${ }^{1}$, Ludovic Reveiz ${ }^{1}$
}

Suggested citation Carracedo S, Palmero A, Neil M, Hasan-Granier A, Saenz C and Reveiz L. The landscape of COVID-19 clinical trials in Latin America and the Caribbean: assessment and challenges. Rev Panam Salud Publica. 2020;44:e177 https://doi. org/10.26633/RPSP.2020.177

\begin{abstract}
A considerable number of clinical trials is being conducted globally in response to the COVID-19 pandemic, including in low- and middle-income countries such as those in the Latin America and Caribbean region (LAC). Yet, an abundance of studies does not necessarily shorten the path to find safe and efficacious interventions for COVID-19. We analyze the trials for COVID-19 treatment and prevention that are registered from LAC countries in the International Clinical Trials Registry Platform, and identify a trend towards small repetitive non-rigorous studies that duplicate efforts and drain limited resources without producing meaningful conclusions on the safety and efficacy of the interventions being tested. We further assess the challenges to conducting scientifically sound and socially valuable research in the LAC region in order to inform recommendations to encourage clinical trials that are most likely to produce robust evidence during the pandemic.
\end{abstract}

Keywords Coronavirus infections; clinical trial; ethics, research; public health policy; Latin America; Caribbean Region.

During the SARS-CoV-2 pandemic the urgency to conduct research to find safe and efficacious treatments and vaccines has led to a sizable proliferation of COVID-19 clinical trials. A rapid reaction of the scientific community to advance research during this outbreak has resulted in multiple COVID-19 trials conducted in several countries around the world, including low and middle-income countries (LMICs), such as those in Latin America and the Caribbean (LAC) (1). Given the rising numbers of COVID-19 cases and deaths recorded in the LAC region, research has become a fundamental endeavor to respond to the pandemic. However, the volume of studies being conducted in LAC within a compressed time frame and challenges in the registration of clinical trials have made it difficult to understand and assess the research that is being conducted. This paper presents an overview and analysis of the clinical trials for treatment and prevention of COVID-19 in the LAC region in order to assess the challenges and inform recommendations to ensure that these research efforts are able to generate meaningful evidence.

\section{METHODS}

We searched in the International Clinical Trials Registry Platform (ICTRP) of the World Health Organization (WHO) for registered COVID-19 clinical trials in countries and territories of LAC from the beginning of the pandemic to August 19. While the primary goal of ICTRP is the registration of clinical trials, observational studies and expanded access protocols are sometimes registered. Additionally, ICTRP may not include all clinical trials being conducted in LAC as registering trials into registries that feed ICTRP is not required in some countries.

\footnotetext{
1 Pan American Health Organization, Washington, DC, United States of America.

$\triangle$ Carla Saenz, saenzcar@paho.org
} 


\section{RESULTS}

In the Region, only three countries (Brazil, Cuba and Peru) have primary registries that provide clinical trials data to ICTRP (2). Despite these limitations, ICTRP provides the most accurate picture of the research conducted in LAC. Of the 5213 COVID-19 trials registered, a search was made by the 47 countries and territories of the LAC region. We identified 285 studies being conducted in the region. 79 are registered as observational studies and 206 as interventional studies. Two entries explicitly indicate interventions being provided through compassionate use or expanded access programs. 170 of the interventional studies registered in ICTRP test products for treatment and prevention. The following overview is based on this subset of clinical trials.

Brazil, followed by Mexico and Argentina, have the highest number of registered COVID-19 trials. Combined, they make up $75.8 \%$ of the total of clinical trials for treatment and prevention registered from the Region (Table 1). 18.2\% of clinical trials registered from LAC are multi-country studies, all of which involve collaborations with countries outside the Region. No regional collaborative research initiative was found. Two trials correspond to global research efforts; one is the WHO's Solidarity trial that is being conducted in five LAC countries. Most of the multi-country trials are sponsored by the pharmaceutical industry. $78.4 \%$ of the single-country trials have non-commercial sponsors.

141 studies are randomized trials. 77 of them are controlled with at least partial blinding and represent $45.3 \%$ of the total of trials registered. 104 clinical trials $(61.2 \%)$ have sample sizes of 200 or fewer. The minimum sample size of the clinical trials registered is nine and the maximum is 115000 from a vaccine trial.

$87.6 \%$ of the clinical trials are focused on treatment for COVID-19 rather than on preventive interventions. The vast majority of interventions tested in the Region have other approved clinical uses. Convalescent plasma, antimalarials and antivirals are the most studied type of interventions (Figure 1). In total, there are 98 different potential therapeutics and vaccines being tested in LAC; 6 of these are combination therapies, 84 are mono-therapies, and 8 are vaccines (2 are repurposed and 6 are SARS-CoV-2 vaccines). Three of the 98 are new investigational therapeutics and a COVID-19 vaccine being tested

TABLE 1. Number of clinical trials for treatment and prevention of COVID-19 registered in WHO/ICTRP from LAC countries, March - August 19, 2020

\begin{tabular}{|c|c|}
\hline Country & $\#$ \\
\hline Brazil & 71 \\
\hline Mexico & 52 \\
\hline Argentina & 24 \\
\hline Colombia & 15 \\
\hline Cuba & 12 \\
\hline Peru & 12 \\
\hline Chile & 9 \\
\hline Ecuador & 2 \\
\hline Puerto Rico & 3 \\
\hline Honduras & 1 \\
\hline Dominican Republic & 1 \\
\hline Total & 202 \\
\hline
\end{tabular}

exclusively in Cuba (CIGB 300, CIGB-2020, CIGB-258 peptide and FINLAY-FR-1). As in the rest of the world, convalescent plasma, hydroxychloroquine/chloroquine (HCQ/CQ), and azithromycin are the three most popular interventions being studied in LAC (3).

Many countries are testing the same interventions in multiple trials. For instance, there are 27 single-country trials studying convalescent plasma in the Region, and most of them have small sample sizes $(<100)$. In Mexico, for example, seven plasma studies enroll a total of 281 participants. Regarding HCQ/CQ (either alone or in tandem with another drug), there are 26 studies, of which 14 are being conducted in Brazil. Of note, the recruitment status of $70.3 \%$ of the HCQ/CQ clinical trials is active.

In regard to the population, the majority of the clinical trials include only adults (above 18 years of age). Children can participate in 11 clinical trials, with one month as the minimum age in inclusion criteria. Only one registered trial is specific about including pregnant women, which is unclear in 44 trials. In the rest of the studies $(73.5 \%)$, pregnant women are excluded. To date, none of the COVID-19 clinical trials registered from LAC has completed the item referred in ICTRP.

\section{DISCUSSION}

From the total of COVID-19 clinical trials conducted globally for treatment and prevention of COVID-19, a sizable amount of trials $(10.2 \%)$ is being conducted in LAC according to ICTRP. As for the design, a significant number of clinical trials identified has very small sample sizes and no control group. They are therefore not capable of producing sound evidence on the safety and efficacy of the interventions b eing t ested. L essons learnt from previous outbreaks have demonstrated that research efforts during epidemics should focus on well-designed randomized controlled trials with a large number of participants to produce robust evidence rapidly $(4,5)$. Designs that render trials unable to answer the scientific question of the $\mathrm{s}$ tudy compromise their validity and are ethically problematic because participants are being exposed to risks without the prospect of benefits as a result (i.e. valuable knowledge). As long as small, non-controlled studies are being conducted in the region, research efforts are not being geared towards producing the knowledge that is needed to respond to the pandemic.

Furthermore, trials in LAC often tested the same interventions, leading to a high share of small and repetitive studies. There is also a lack of multicenter studies at national and regional levels, which may reveal weaknesses in coordination and collaboration at both levels. A lack of experience in the design and implementation of large multicenter trials in the Region, research infrastructure constraints, and the challenging context posed by the pandemic might further explain this. Without effective mechanisms in place to coordinate and collaborate, researchers fail to team up and share data. Lack of coordination also leads to the collection of diverse data sets, which hinders comparisons between potential investigational interventions. Within the same jurisdictions, it leads to competition for the recruitment of participants for similar studies, which delays reaching the studies' sample size.

In order to advance coordination and avoid duplication of research efforts, researchers need to be able to know which studies are already being conducted. Adequate clinical trial 


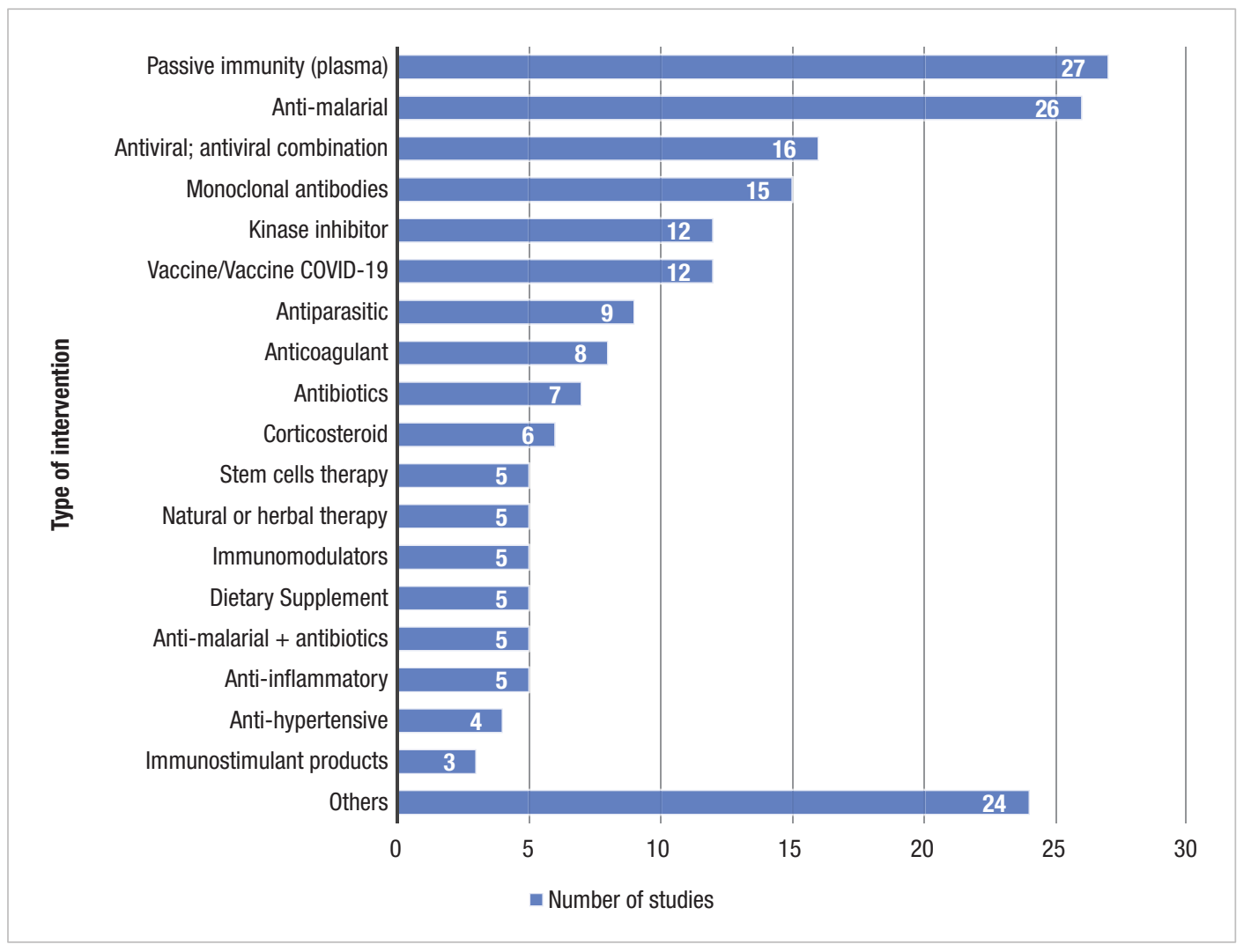

registration that is complete, centralized and publicly available is thus indispensable. Countries must therefore require the registration of all clinical trials in registries that feed into ICTRP. Currently, some LAC countries lack a mechanism to register clinical trials and some have national clinical trials registries that are not publicly available or do not feed into ICTRP (6). It is also crucial for ICTRP to function optimally. Due to heavy traffic during the pandemic, the search function of the portal was not working and only a database file of the COVID-19 trials registered globally could be downloaded from the website. Further challenges were posed by registry entries lacking complete information about the trials and miscategorized studies.

It can however be argued that, to advance rapid collaboration between research teams in the context of the pandemic, even adequate clinical trial registration does not suffice. By the time trials are registered, protocols have been elaborated, obtained ethics approval and are ready to recruit participants. Mechanisms for researchers to share their plans at a prior stage, which facilitate teaming up towards multi-center trials, seem necessary. Devising and implementing such mechanisms is a challenge to improve our response to the pandemic and future emergencies.

Concerning the interventions under study, LAC trials persist on primarily testing interventions that are potentially harmful, show a low rate of success, or have been proven futile, such as HCQ/CQ, hydroxychloroquine and azithromycin, or lopinavir/ritonavir $(7,8,9)$. The rapid development of scientific evidence during the pandemic poses the need to oversee trials being conducted in order to ensure they continue to have social value and are justified both scientifically and in light of their risk-benefit profile. LAC countries should strengthen mechanisms to supervise COVID-19 clinical trials and take necessary action, which includes the termination and modification of trials that are no longer justified or lack a favorable risk-benefit profile and are thus not ethical. Doing so will further avoid participants being exposed to unnecessary risks and valuable resources being used in futile research. Moreover, the paucity of studies on new interventions suggests the need to enhance capacity in basic sciences, the conduct of local clinical trials and fostering innovation.

Regarding the study population, the LAC trials that were assessed tend to systematically exclude children, adolescents, and pregnant and lactating women (10). Lopinavir/ ritonavir and hydroxychloroquine are already used by pregnant women with HIV-infection and malaria, respectively; remdesivir has been tested in pregnant women during the Ebola outbreak; and women with multiple sclerosis receive interferon beta while pregnant $(11,12,13)$. Yet pregnant women are being excluded from trials testing interventions with these drugs. SARS-CoV-2 infection could affect anyone, and the generalized exclusion of these groups without an adequate justification deprives them of the potential benefits of research.

Despite being hit very hard during the pandemic, the vast amount of research being conducted in the Region as part of the COVID-19 response reveals increased capacities and pending challenges. Efforts are still needed to maximize LAC's capacity to conduct trials that produce sound evidence and make the most of scarce resources. Large, multi-country, well-designed, 
randomized, controlled clinical trials that test interventions with promising results based on updated evidence while including participants equitably must be prioritized, for which early on coordination and collaboration across multiple research teams is indispensable. Adaptive platform trials with multiple arms investigating different interventions simultaneously are considered the best option during the pandemic to produce rapid results across a range of treatment options according to harmonized endpoints and outcomes $(14,15,16)$. More participation of the LAC countries in such global efforts as the WHO Solidarity Trial and the development of similar regional research collaborations should be encouraged with a view to further building local capacity.

Finally, the challenges posed by the COVID-19 pandemic highlight the need to strengthen national research systems, and national research ethics systems within them, aimed at ensuring that research is effective and adheres to the highest ethical standards in order to inform decision-making during and after the pandemic. The Pan American Health Organization (PAHO)'s ongoing efforts to strengthen LAC's capacities to conduct rigorous ethical research should escalate to foster networks of collaborative research across the Region that are capable of catalyzing effective, high impact research. Well-established national research systems and collaborative networks will allow LAC countries and territories to be better prepared for research response for health emergencies in the future.

\section{CONCLUSION}

Our assessment of the clinical trials conducted in the Region reveals a trend towards small, repetitive non-rigorous studies that duplicate efforts and drain limited resources without yielding sound evidence on the safety and efficacy of the interventions being tested. LAC countries need to join efforts and direct resources towards therapeutics with a greater success rate. Well-designed, high-quality randomized controlled clinical trials with large sample sizes and fair inclusion criteria are best positioned to contribute meaningfully to the discovery of safe and efficacious therapeutics and vaccines for COVID-19. Mechanisms of coordination and collaboration for clinical trials within and across the countries of the Region, clinical trials registration in public and globally searchable registries feeding into ICTRP, more participation in research global efforts, and the strengthening of national research systems are key elements to improve our regional research response to the COVID-19 pandemic and beyond.

Author contributions. Conception and design of the work: $\mathrm{AP}, \mathrm{SC}, \mathrm{NM}$, AHG, CS, LR; literature search: AP, SC, CS, LR; data collection: $\mathrm{AP}, \mathrm{SC}, \mathrm{NM}, \mathrm{AHG}$; analysis and interpretation of data: AP, SC, NM, AHG, CS, LR; drafting manuscript: AP, SC, NM, CS, LR; revisions of manuscript: AP, SC, NM, CS, LR; approval of final manuscript: AP, SC, NM, AHG, CS, LR. SC and AP contributed equally and are first authors of this article.

\section{Conflict of interests. None declared.}

Funding. The study was partially funded by the Wellcome Trust, grant 220028/Z/19/Z.

Disclaimer. Authors hold sole responsibility for the views expressed in the manuscript, which may not necessarily reflect the opinion or policy of the RPSP/PAJPH and/or PAHO.

\section{REFERENCES}

1. World Health Organization. A Coordinated Global Research Roadmap: 2019 Novel Coronavirus. R \& D Blueprint. [Internet] 12 March 2020. [cited 27 Aug 2020]. Available from: https://www.who.int/ publications $/ \mathrm{m} /$ item/a-coordinated-global-research-roadmap

2. World Health Organization. International Clinical Trials Registry Platform, Primary Registries [Internet]. (Geneva). [updated 26 August 2020; cited 28 Aug 2020]. Available from: http:/ / www.who. int/ictrp/network/primary/en/

3. Rafel JB, Marin M, Heaney T. Covid-19 Clinical Trials Explorer. [Internet: Tableau Software]. 24 April 2020. [updated 19 June 2020; cited 27 August 2020. Available from: https://public. tableau.com/profile/marinamarin\#! / vizhome/covidTrials / COVID-19ClinicalTrialsExplorer

4. London AJ, Kimmelman J. Against pandemic research exceptionalism. Science. 2020 May 1;368(6490):476-7. doi: 10.1126/science.abc1731.

5. Lane HC, Fauci AS. Research in the Context of a Pandemic [published online ahead of print, 2020 Jul 17]. N Engl J Med. 2020;NEJMe2024638. doi:10.1056/NEJMe2024638.

6. García-Vello P, Smith E, Elias V, Florez Pinzon C, Reveiz L. Adherence to clinical trial registration in countries of Latin America and the Caribbean, 2015. Rev Panam Salud Publica. 2018;42:e44. doi. org/10.26633/RPSP.2018.44

7. University of Oxford. RECOVERY Trial [Internet]. [cited 2020 Aug 31]. Available from: https://www.recoverytrial.net/

8. National Institutes of Health. What's new in the guidelines COVID-19 Treatment Guidelines. [Internet]. [updated 3 November 2020; cited 31 August 2020]. Available from: https://www.covid19treatment guidelines.nih.gov/whats-new /
9. Pan American Health Organization. Ongoing Living Update of Potential COVID-19 Therapeutics: summary of rapid systematic reviews. [updated 16 June 2020; cited 27 August 2020]. Available from: https://iris.paho.org/bitstream/handle/10665 .2/52294/PAHOIMSEIHCOVID-19200008_eng.pdf?sequence $=1 \&$ is Allowed $=\mathrm{y}$

10. Hwang TJ, Randolph AG, Bourgeois FT. Inclusion of Children in Clinical Trials of Treatments for Coronavirus Disease 2019 (COVID19). JAMA Pediatr. Published online 7 May 2020. doi:10.1001/ jamapediatrics.2020.1888s

11. ClinicalInfo.hiv.gov. [Internet] Lopinavir/Ritonavir (Kaletra, $\mathrm{LPV} / \mathrm{r}$ ): Recommendations for the Use of Antiretroviral Drugs in Pregnant Women with HIV Infection and Interventions to Reduce Perinatal HIV Transmission in the United States. Office of AIDS Research. [updated 24 December 2019; cited 27 August 2020]. Available from: https://clinicalinfo.hiv.gov/en/guidelines/perinatal/ lopinavirritonavir-kaletra-lpvr

12. Mulangu S, Dodd LE, Davey RT, Tshiani Mbaya O, Proschan M, Mukadi D, et al. A Randomized, Controlled Trial of Ebola Virus Disease Therapeutics. N Engl J Med. 2019 Dec 12;381(24):2293-2303. doi: 10.1056/NEJMoa1910993.

13. Hellwig K, Geissbuehler Y, Sabidó M, Popescu C, Adamo A, Klinger $\mathrm{J}$, et al. Pregnancy outcomes in interferon-beta-exposed patients with multiple sclerosis: results from the European Interferon-beta Pregnancy Registry. J Neurol. 2020 Jun;267(6):1715-1723. doi: 10.1007/s00415-020-09762.

14. Eichler HG, Cavaleri M, Enzmann H, Scotti F, Sepodes B, Sweeney F, Vamvakas S, Rasi G. Clinical trials for Covid-19: can we better 
use the short window of opportunity? Clin Pharmacol Ther. 2020 May 14. doi:10.1002/cpt.1891

15. European Medicines Agency, Human Medicines Committee (CHMP). Call to pool research resources into large multi-centre, multi-arm clinical trials to generate sound evidence on COVID-19 treatments. [Press Release] (19 March 2020) [cited 27 August 2020). Available from: https://www.ema.europa.eu/en/documents/ press-release / call-pool-research-resources-large-multi-centre -multi-arm-clinical-trials-generate-sound-evidence_en.pdf

16. Pan American Health Organization. Considerations for Regulatory Oversight of Clinical Trials in the COVID-19 Pandemic.
5 June 2020. [cited 27 August 2020]. Available from: https:// www.paho.org/en/documents/considerations-regulatory -oversight-clinical-trials-covid-19-pandemic

Manuscript received on 15 October 2020; revised version accepted for publication on 19 November 2020.

\section{El panorama de los ensayos clínicos sobre COVID-19 en América Latina y el Caribe: evaluación y desafíos}

RESUMEN Se está llevando a cabo un número considerable de ensayos clínicos en todo el mundo en respuesta a la pandemia de COVID-19, incluso en países de ingresos bajos y medios como los de la región de América Latina y el Caribe. Sin embargo, la abundancia de estudios no necesariamente acorta el camino para encontrar intervenciones seguras y eficaces frente a la COVID-19. Se analizaron los ensayos para el tratamiento y la prevención de la COVID-19 de los países de América Latina y el Caribe que están registrados en la Plataforma de Registros Internacionales de Ensayos Clínicos de la Organización Mundial de la Salud, y se identificó una tendencia hacia la realización de estudios pequeños, repetitivos y no rigurosos que duplican los esfuerzos y merman recursos limitados sin producir conclusiones significativas sobre la seguridad y la eficacia de las intervenciones evaluadas. Se evaluaron asimismo los desafíos que plantea la realización de investigaciones científicamente sólidas y socialmente valiosas en la región de América Latina y el Caribe a fin de brindar recomendaciones que alienten la realización de ensayos clínicos que tengan más probabilidades de producir evidencia sólida durante la pandemia.

Palabras clave Infecciones por coronavirus; ensayo clínico; ética en investigación; políticas públicas de salud; América Latina; Región del Caribe. 